\title{
Defensa, solidaridad y apoyo a los presos políticos. La COFAPPEG (1970-1976) ${ }^{1}$
}

\author{
Defense, solidarity and support for political prisoners. The COFAPPEG \\ (1970-1976)
}

\author{
Marianela Scocco \\ mariascocco@gmail.com \\ Investigaciones Socio-históricas Regionales - Conicet \\ - Facultad de Humanidades y Artes, Universidad \\ Nacional de Rosario, Argentina
}

Recepción: 17 Mayo 2020

Aprobación: 20 Noviembre 2020

Publicación: 04 Enero 2021

Cita sugerida: Scocco, M. (2021). Defensa, solidaridad y apoyo a los presos políticos. La COFAPPEG (1970-1976). Trabajos y Comunicaciones, (53), e132. https://doi.org/10.24215/23468971e132
Resumen: La defensa de presos políticos tiene larga data en Argentina, pero fue en los primeros años de la década de 1970, con el incremento de la represión y de la cantidad de detenidos políticos, que se experimentó la creación de organizaciones dedicadas exclusivamente a este problema. Estas agrupaciones de defensa, solidaridad y apoyo a los presos políticos, estudiantiles, gremiales y sociales, estaban constituidas principalmente por familiares de las personas detenidas pero tenían reconocidos vínculos con algunas organizaciones políticas y político-militares. Este artículo indaga sobre una de las más importantes del periodo: la Comisión de Familiares de Presos Políticos, Estudiantiles y Gremiales (COFAPPEG).

Palabras clave: Comisión, Defensa, Solidaridad, Presos políticos.

Abstract: The defense of political prisoners has a long history in Argentina, but it was in the early years of the 1970s, with the increase in repression and the number of political detainees that the creation of organizations dedicated exclusively to this problem was experienced. These groups of defense, solidarity and support for political, student, union and social prisoners were mainly made up of families of the detainees but had recognized links with some political and political-military organizations. This article investigates one of the most important of the period: the Commission of Relatives of Political Prisoners, Students and Trade Unions (COFAPPEG).

Keywords: Commission, Defense, Solidarity, Political prisoners.

COFAPPEG, como su nombre lo dice, es un nucleamiento de familiares de presos politicos, estudiantiles o gremiales del régimen. Nuestro objetivo, como no puede dudarse dado nuestro carácter de familiares que estamos orgullosos de los seres que están detenidos, no ha sido otro que luchar para obtener la libertad de los mismos. En nuestro que hacer, al cabo de dos años, no obstante, hemos tenidos que afrontar una gran cantidad de problemas vinculados con el tratamiento dado a los detenidos, fundamentalmente agravado a partir de la ley 19.863 nos hemos ocupado en la medida de nuestras posibilidades de aliviar los múltiples problemas económicos por los que atraviesan las familias dependientes; se ha tratado de mantener el mayor contacto posible con los presos para mantener latente la unión familiar y hacerles sentir 


\section{la adhesión y comprensión de su lucha por los amigos y población en general; se han enfocado los tratamientos de problemas y programas a nivel nacional con otras similares a las nuestras $y$, en fin, se ha luchado con la ayuda de distintas agrupaciones denunciando las torturas, las aberraciones de toda la legislación represiva y dando a conocer los motivos que impulsaron a nuestros familiares, hoy presos o muertos, a emprender una actitud de combate. "Entrevista con COFAPPEG", revista Posición, ${ }^{2}$ abril/mayo de 1973 p.10.}

\section{INTRODUCCIÓN}

En Argentina, a partir de 1969, como sostiene Mónica Gordillo (2003), se registró un momento explosivo, con la emergencia de lo acumulado en los años previos, cuando estalló la rebelión popular y se fueron conformando movimientos sociales en oposición a la dictadura de la "Revolución Argentina” (1966-1973) que ensayaron nuevos métodos de acción. A partir de entonces se produjo el aumento de la actividad represiva del Estado, que comprendió detenciones masivas y la represalia de diversas manifestaciones populares. ${ }^{3}$ Inclusive, una parte de esa represión adoptó un carácter clandestino a través de algunas operaciones desplegadas por los servicios de inteligencia y los grupos paraestatales, llevando adelante amenazas, atentados, secuestros, desapariciones y asesinatos. Esa actividad represiva generó la reacción de diversos sectores y la conformación de distintas organizaciones defensistas ${ }^{4}$ de presos políticos, estudiantiles, gremiales y sociales que comenzaron a llenar las cárceles del país.

Si bien estas organizaciones han sido poco estudiadas, algunos autores han comenzado a reconocer en ellas un antecedente directo del Movimiento de Derechos Humanos que posteriormente se formó en Argentina (Oviedo y Solis, 2006; Solis, 2014; Alonso, 2011; Kotler, 2014; Eidelman, 2010 y 2009; Scocco, 2020). Sin embargo, esto no significa que -en todos los casos- haya existido continuidad ni que hayan sido expresiones relativamente homogéneas.

De esta forma, además de la Liga Argentina por los Derechos del Hombre (LADH), que venía defendiendo presos políticos desde los años 30, lo que aparece como novedoso en este momento -denotado por la persecución a militantes peronistas tras el golpe de Estado de 1955- es la incorporación de un nuevo actor a la defensa de presos políticos: los abogados de filiación peronista. Estos se reunieron, a principios de la década de 1960, en la Comisión de Familiares de Detenidos (COFADE), que constituyó el primer nucleamiento defensista a nivel nacional, próximo al peronismo, conformado por familiares, abogados y activistas, en respuesta a la aplicación del Plan Conintes. Según Mauricio Chama: "Esta entidad, que a diferencia de la LADH funcionó con un grado mínimo de institucionalización, había sido concebida por un reducido grupo de familiares y militantes peronistas en el año 1960 en respuesta a la puesta en marcha del plan Conintes por parte del gobierno de Frondizi" (2016, p. 111). ${ }^{5}$

Para finales de los años 60, se conformó el cuerpo de abogados de la Confederación General del Trabajo de los Argentinos (CGTA), surgida en abril de 1968, orientado a la defensa de los presos por cuestiones gremiales. También es interesante destacar que los cuerpos de abogados de la CGTA y de la LADH fueron los antecedentes directos de las agrupaciones de profesionales del derecho que comenzaron a formarse por entonces en ciudades como Rosario, Córdoba y Buenos Aires que estuvieron vinculadas a la defensa de los presos políticos.

La primera de ellas se constituyó en Rosario en el año 1968. Denominada Agrupación de Abogados de Rosario (AAR), estaba integrada por un grupo de letrados con una marcada oposición a la dictadura militar. Este grupo asumió la defensa de los presos políticos, cualquiera fuera su pertenencia, desde su fundación y mientras perduró la dictadura (1968-1973) (Bereciartúa, 2013).

En Buenos Aires, la Asociación Gremial de Abogados (AGA), comúnmente conocida como "la Gremial", se gestó a mediados de 1971. Según Chama: “(...) se diferenció de nucleamientos preexistentes, como 
COFADE o la LADH, porque estaba exclusivamente integrada por profesionales del derecho. A su vez, la AGA se conformó en contraposición con los organismos profesionales que agrupaban a los abogados la Capital Federal, que se negaban a asumir la actividad defensiva, como el 'conservador' Colegio de Abogados, o bien mantenían una actitud vacilante, como la 'liberal' Asociación de Abogados de Buenos Aires" (2010, p. 201). En la ciudad de Córdoba también se formalizó la Agrupación de Abogados de Córdoba para 1971 (Oviedo y Solís, 2006).

Ahora bien, a partir de la década de 1970 la defensa y solidaridad con los presos políticos adquirió una presencia y una consistencia activista, corporativa y profesional aún mayor que en la década anterior y se crearon organizaciones dedicadas exclusivamente a este problema. Sus acciones en apoyo, solidaridad y defensa a los presos se intensificaron especialmente en la etapa 1971-1973 en función del crecimiento numérico de los detenidos políticos y la transformación cualitativa de la represión durante la última etapa de la dictadura de la "Revolución Argentina". Para el año 1971 al menos, se puede reconocer la existencia de distintas agrupaciones defensistas de alcance nacional, con reconocidos vínculos con algunos partidos políticos y organizaciones político-militares. En este amplio abanico de agrupaciones, a pesar de sus diferentes adscripciones políticas e ideológicas, se definió como horizonte compartido la defensa y solidaridad con los presos políticos y la denuncia pública de sus condiciones de detención. Lo cierto es que, como sostiene Carol Solis (2014, p.132), "Más allá de las diferencias en formato, origen y composición, tenían en común la demanda generalizada de liberación de los detenidos y la denuncia sobre las condiciones de encierro y los traslados disciplinadores".

Entre ellas, una de las más destacadas fue la Comisión de Familiares de Presos Políticos, Estudiantiles y Gremiales (COFAPPEG). Surgida en 1971 en distintas ciudades del país, como sostiene Eidelman:

"La COFAPPEG integró y organizó a los familiares de los militantes y combatientes presos, la gran mayoría sin experiencia política previa. Acompañando el desarrollo y la actividad política y militar del PRT-ERP de esos años, la comisión tuvo un origen en las provincias del interior del país y, recién en 1972, se constituyó en la Capital. COFAPPEG llegó a tener presencia en Buenos Aires, Rosario, Córdoba, Tucumán y Santa Fe, y alcanzó su desarrollo y actividad culminantes entre la huelga de hambre de la Navidad de 1972 y la liberación del conjunto de los presos, en mayo del 73" (2009, p. 21).

A través de un conjunto de fuentes variadas, que oscilan desde entrevistas, volantes y publicaciones de las organizaciones y partidos hasta prensa de diversa índole y documentos de los servicios de inteligencia ubicados en el archivo de la ex Dirección de Inteligencia de la Policía de la provincia de Buenos Aires (DIPBA) y en el fondo documental de la ex Dirección General de Informaciones (DGI), alojado en el Archivo Provincial de la Memoria de la provincia de Santa Fe (APMSF), en este artículo analizo el surgimiento y desarrollo de la COFAPPEG entre los años 1970 y 1976.

\section{LOS INICIOS DE LA COFAPPEG}

La COFAPPEG comenzó a funcionar desde mediados del año 1971 al calor del aumento de las detenciones llevadas a cabo a militantes populares, que se definían como presos políticos. En sus orígenes, esta Comisión se autodefinía como autónoma, es decir, como no dependiente de ninguna otra organización o partido, aclarando que contaba con sus propios recursos económicos:

\footnotetext{
"COFAPPEG está constituida exclusivamente por familiares de presos políticos, estudiantiles y gremiales, es autónomo o sea que no depende de ninguna otra entidad o agrupación, se maneja con sus propios fondos y su finalidad primordial es el apoyo A TODOS LOS PRESOS SOCIALES Y FAMILIARES DEPENDIENTES SIN INTERESAR A QUE GRUPO PERTENECEN, toda vez que entendemos que TODOS Y CADA UNO LUCHA CONTRA 'EL ENEMIGO COMUN '. POR LA LIBERTAD DE TODOS LOS PRESOS - VIVA LA PATRIA!".
}

Pese a lo anterior, de ciertos documentos y entrevistas consultadas se desprende que la COFFAPEG tenía vínculos con el Partido Revolucionario de los Trabajadores - Ejército Revolucionario del Pueblo (PRT- 
ERP). ${ }^{7}$ Sin embargo, aún es difícil precisar si es adecuado considerar a esta Comisión como un brazo legal del PRT-ERP, efectivamente impulsado por ese espacio, o bien como una comisión frentista hegemonizada en algunas etapas y localidades por el PRT-ERP.

Los frentes legales del $\mathrm{PRT}^{8}$ tuvieron un importante desarrollo desde 1970, cuando tomó impulso la COFFAPEG que, según Pasquali (2011), si bien no tenía identificación partidaria, en la región del gran Rosario quienes la coordinaban eran los familiares y militantes del PRT-ERP. Para Oviedo y Solís (2006), en Córdoba, la mayoría de los integrantes iniciales de la COFAPPEG eran madres y padres de miembros tanto del ERP como de Montoneros. Como anticipé, Eidelman reconoce que la COFAPPEG tuvo su origen en el "interior del país" y que en Buenos Aires surgió recién en 1972, producto de una división entre familiares de presos de diferentes organizaciones político-militares peronistas y marxistas. Afirma que:

"Originalmente, los familiares de presos de Montoneros, FAP, FAL, FAR y ERP trabajaron en forma unitaria en la Capital,
funcionando en común con el apoyo de todas las organizaciones armadas. Fue recién a mediados de 1972 que, por presión
de los familiares más vinculados a Montoneros y ante la apuesta del peronismo por la salida institucional y las elecciones,
se produjo una separación de los familiares de presos peronistas de los familiares de presos de la izquierda. Ante la división,
surge en la Capital la COFAPPEG, diferenciada de la comisión de familiares de presos peronistas. El PRT ocupó un lugar
de dirección de la COFAPPEG por su propio peso político y por el hecho de contener en sus filas una gran cantidad de
los detenidos (...) De todas formas, no todos los familiares de presos peronistas siguieron esa orientación. Familiares sin
identidad peronista de presos recientemente peronizados se sumaron a COFAPPEG, como varias mujeres de presos de las
FAR" (2009, pp.27-28).

De esta manera y por lo que he podido reconstruir, la COFAPPEG se originó en Rosario con el grupo de familiares de combatientes detenidos que realizaron el asalto de la Comisaría 20 en el barrio Empalme Graneros, el 27 de abril de $1970 .{ }^{10}$ Comenzaron a reunirse a finales de ese año a partir de la situación de sus parejas e hijos. Según uno de esos combatientes, Rubén Suarez, el grupo que cae con el asalto a la comisaria 20 no era todavía del PRT, ni siquiera funcionaba el ERP en Rosario. Suarez sostiene que:

"En la cárcel, con los compañeros que no éramos del PRT, no éramos ni del PRT ni del ERP, éramos un grupo foquista que queríamos la lucha armada y, por eso nos ponemos a trabajar en conjunto con el PRT, hasta que en la cárcel vemos la situación y decimos bueno nos incorporamos al PRT. Claro yo era del grupo Massetti (...). Entonces nos encontramos con la gente del PRT y dentro de la cárcel hicimos un proceso de discusión (...). Entonces decidimos incorporarnos al PRT”. 11

Finalmente, hacia el año 1971 todos ellos confluyeron en el PRT desde su encierro, mientras que sus familiares y parejas realizaban un acercamiento paralelo con los frentes legales del partido fuera de la cárcel. De esta forma, es posible afirmar que en el núcleo original de la COFAPPEG en Rosario sus integrantes tenían vínculos con el PRT al tiempo que su organización fue impulsada por este partido. Cristina Rodríguez, pareja de Rubén Suárez, sostiene que: "La COFAPPEG nació en Rosario. COFAPPEG era Comisión de Familiares de Presos Políticos, Estudiantiles y Gremiales, primero Comisión de Presos Políticos pero después se empezaron a agregar los estudiantes que iban cayendo, más los gremialistas, y bueno entonces le pusimos así". ${ }^{12}$ Para Suárez, el nombre estaba relacionado con la distinción de los detenidos que hacían las autoridades en las cárceles, especialmente entre políticos y gremiales. ${ }^{13}$

La COFAPPEG fue la comisión de solidaridad con los presos políticos más importante de Rosario, aunque al mismo tiempo, fue la menos registrada por la prensa. Pasquali advirtió esto y sostuvo que: "Las menciones en los diarios locales a aquello que nosotros podemos reconocer como indicadores de inserción son ocasionales. Por ejemplo, la COFAPPEG tiene muy escasa presencia en la prensa” (2011, p. 26). En esta reconstrucción, solo encontré a la COFAPPEG en los diarios rosarinos en una conferencia de prensa, con motivo del lanzamiento de una huelga de hambre, que coincide con su aparición pública.

Por esta razón, pese a aquella reunión incipiente desde finales de 1970, la COFAPPEG no hizo su presentación como tal hasta diciembre de 1971, año en que participaron de la huelga de hambre impulsada por los sacerdotes tercermundistas. En esa ocasión, la COFAPPEG convocó a una conferencia de prensa 
en el local de la Asociación de Trabajadores del Estado (ATE) que salió en los diarios locales La Tribuna y Crónica, ${ }^{14}$ donde informaba el inicio de la huelga. Para sus protagonistas, esa conferencia también fue la aparición pública de la Comisión, una suerte de momento fundacional. Según Cristina Rodríguez, hasta entonces se reunían en un bar pero a partir de allí contemplaron la necesidad de tener un espacio de encuentro:

"Ya a fines del '70 nosotros nos reuníamos como familiares en el bar de Corrientes y Wheelwright, en frente de la estación, estaba sobre la ochava Este, que ahí íbamos los familiares. Que en ese momento, la coordinadora por el PRT era Liliana Montanaro. ${ }^{15}$ Con ella empezamos el recorrido de familiares y después ya cuando nos queda chico (...) pedimos un lugar grande y después de caminar mucho, porque no teníamos plata para alquilar un local, caímos en ATE, y ahí hablamos con el Negro Aguirre, ${ }^{16}$ y el Negro Aguirre nos dice que sí, que teníamos la sala principal de reuniones y ahí nace la COFAPPEG. Hacemos una conferencia de prensa, llamamos a los medios". ${ }^{17}$

Cuando empezaron a caer presos otros militantes, incluso de otras adscripciones partidarias, los integrantes de la COFAPPEG comenzaron a ir a la casa de cada familiar a invitarlos para que participaran. De esta forma, el grupo fue creciendo. Además de convocarlos a trabajar en conjunto, intentaban atender las diversas necesidades que tenían los familiares de los presos. Realizaban tareas en los barrios, repartían volantes explicando qué era un preso político y cuáles eran sus necesidades. Por último, según Cristina Rodríguez, no recibían dinero ni del PRT ni de ninguna otra entidad, sino que se financiaban con la realización de peñas y otras actividades para recaudar fondos. Era una política del partido que cada frente legal buscara su propio financiamiento.

El 11 de enero de 1972 fueron detenidos en Rosario, Ricardo Silva, Mónica Raquel Muro, Julio Ángel Santa Cruz y Segundo Telésforo Gómez. ${ }^{18}$ Cristina ubica esta caída como otro momento de crecimiento de la COFAPPEG, a partir de un aumento estratégico de la organización en defensa de esos presos que eran del PRT. Solis (2014) también resalta, para el caso de Córdoba, que una de sus entrevistadas rememora como evento disparador de la formación de la COFAPPEG en dicha ciudad a las detenciones de militantes de las nacientes organizaciones político-militares y los signos de tortura que sus familiares habían advertido.

En consonancia con esto, pero a diferencia de lo ocurrido en Buenos Aires, en Rosario -aunque funcionaban otras comisiones de presos políticos y a pesar de la adscripción mayoritaria al PRT- la COFAPPEG se mantuvo trabajando con familiares de distintos sectores:

\footnotetext{
"Rosario fue la única regional que trabajó en conjunto, que no se separó, es decir, nosotros trabajamos peronistas y no peronistas. Y todos los demás lugares, la única regional, después regional Córdoba, Santa Fe, Tucumán, trabajaban 'Comisión de Familiares Peronistas' y 'Comisión de Familiares del PRT’ les decían, de izquierda digamos, pero acá en Rosario no, nosotros incluso trabajamos con la Juventud Peronista Regional II. En ese momento incluso estaba el PST. ${ }^{19}$ En esa época estaban, me acuerdo que ellos incluso colaboraban en la impresión de los volantes". ${ }^{20}$
}

A escala nacional, según Eidelman, la mayor parte de los integrantes de esta Comisión, que eran personas mayores, padres y madres de jóvenes militantes revolucionarios detenidos y en algunos casos hermanos o cónyuges, carecía de experiencia política. Por otra parte, en Rosario, varias comisiones de apoyo y solidaridad con los presos políticos - como el Movimiento Nacional contra la Represión y la Tortura $;{ }^{21}$ la Comisión de Familiares de Presos Políticos ${ }^{22}$ y la COFAPPEG - existieron paralelamente e incluso compartieron algunos de sus miembros. Un ejemplo de ello es Ángel Delfino, el padre de Mario Delfino, que también había sido detenido después del intento de copamiento de la Comisaría 20 de Rosario, el 14 de abril de 1970. Según Francisco Iturraspe, integrante del Movimiento Nacional contra la Represión y la Tortura y de la Comisión de Familiares de Presos Políticos, Ángel Delfino participaba en las dos: “(...) pero no había una competencia, algunos compañeros participan de los dos grupos. Era más chico el grupo [que en Buenos Aires] entonces no había una división muy tajante". ${ }^{23}$ Mientras una integrante de COFAPPEG Rosario relataba: 
"Yo trabajé en el mismo frente hasta el '73, en el frente legal, es decir, hacíamos otras cosas por eso te digo que un comodín fue; y también lo que me gustaba destacar era el rol de los viejos, porque incluso hubo viejos, viejos con cariño, que fueron compañeros... era todo un tema hacerlos participar, porque imaginate, sus hijos habían caído en cana, era todo una novedad. Los padres de Mario Delfino, no eran... eran gente grande, clase media alta, costaba mucho y sin embargo los viejos fueron los que ayudaron en muchas cosas" (Citado en Pasquali, 2011, p. 24).

Al mismo tiempo, algunos de los integrantes que aparecen como fundadores la Comisión de Familiares de Presos Políticos, ${ }^{24}$ son también nombrados por Cristina Rodríguez como miembros de la COFAPPEG.

Otros padres muy activos en la COFAPPEG fueron los de Adriana Cappelletti, que era la esposa de Carlos Alberto del Rey, ambos del PRT. Sus suegros comenzaron a participar por él, que había sido detenido el 27 de abril de 1971. En una entrevista, Adriana recordaba que: "Mis padres estaban encantados con él, y cuando lo encarcelaron formaron parte de la Comisión de Familiares de Presos Políticos, Estudiantiles y Gremiales (Cofappeg), que tanto hizo para visitarlos en la cárcel" (Citado en Tessa, 2012). ${ }^{25}$

Carlos Alberto del Rey y Mario Delfino, ambos del PRT-ERP, fueron asesinados en la masacre de Trelew el 22 de agosto de $1972 .{ }^{26}$ Por entonces se prohibieron los funerales de los fusilados de Trelew en todo el país, pero éstos se convirtieron en verdaderos mítines políticos, ${ }^{27}$ a pesar de la dificultad de llegar a las salas velatorias, ya que estaban rodeadas por vehículos militares. Los cuerpos de Del Rey y Delfino fueron trasladados para ser velados y enterrados. Llegaron a Rosario la noche del 23. Del Rey fue velado y sepultado en el Cementerio de Granadero Baigorria, localidad vecina a $15 \mathrm{~km}$ de Rosario. Delfino fue retirado por sus padres y velado en Rosario. Las fuerzas represivas, a cargo del jefe de la policía, Agustín Feced, intentaron dispersar a quienes conducían el féretro de Delfino. ${ }^{28}$

Estas primeras organizaciones y sus repertorios de acción demuestran que eran espacios plurales en los que familiares y militantes políticos y gremiales convergían en la acción de defensa y solidaridad con los detenidos y en las que resulta difícil reconstruir las fronteras de cada espacio. A su vez, esto es típico de las ciudades más pequeñas que Buenos Aires, como Rosario o Córdoba, donde las personas usualmente circulaban en varios agrupamientos y tenían los mismos lugares de activismo y sociabilidad, por lo que solían ser menos visibles o importantes las divisiones político-ideológicas. Pasquali (2011) sostiene además que experiencias como la de la COFAPPEG, en algunos casos fue el primer paso hacia la militancia y en otros se limitó a ese espacio de activismo.

\section{REPERTORIOS DE ACCIÓN}

Entre los repertorios de acción emprendidos por la COFAPPEG, junto a otras comisiones de solidaridad, se combinaba la asistencia jurídica y material, la denuncia pública y la organización de las visitas de familiares a las cárceles. "La actividad desarrollada incluía la contención de los familiares de los detenidos, seguir la atención de las causas judiciales por parte de los abogados defensores y especialmente la organización de las visitas a los penales" (Eidelman, 2009: 27). El objetivo central era la liberación de los presos pero también buscaba el mejoramiento de las condiciones de detención, como sostenían sus propios integrantes en una entrevista realizada en Córdoba en marzo de 1973, citada en el epígrafe de este artículo.

Eidelman indica que existía una suerte de tensión que caracterizaba la actividad de la COFAPPEG. Por un lado, en el discurso público de la Comisión no se hacía hincapié en la militancia revolucionaria o la actividad militar de los presos, para poder desarrollar tareas de solidaridad en el nivel más amplio posible, incluyendo vínculos con los partidos tradicionales. Pero, por otro lado, algunos familiares participaban de acciones donde se desplegaban banderas de las organizaciones político-militares y los discursos combativos aludían a la actividad política de los represaliados, que se trataba de combatientes y guerrilleros. Suárez recuerda que el padre de Delfino, que incluso había tenido experiencias políticas opositoras a la de la izquierda ("en Italia 
era un camisa negra"), "cuando lo matan a su hijo, él es el que lleva la bandera del ERP adentro del saco para ponérsela arriba del baúl del entierro". ${ }^{29}$

El pedido por la libertad de los presos políticos y la denuncia por las condiciones de detención, como la amplitud de los espacios de participación de esta Comisión, se vieron reflejados en una serie de eventos, actos, movilizaciones, congresos y solicitadas que emprendieron conjuntamente con otras organizaciones. Uno de esos repertorios de acción más utilizados fue la realización de congresos y reuniones en todo el país. Según Cristina Rodríguez, la COFAPPEG hacía dos congresos por año en distintas ciudades:

\footnotetext{
"Se hacían congresos, nosotros teníamos dos congresos de COFAPPEG por año, donde participábamos todos, peronistas y no peronistas, donde se plasmaba todo lo que se iba a hacer, porque había cosas que se hacían en conjunto, planificábamos lo que hacíamos a los largo del año, después cada regional hacia sus cosas participativas para juntar plata, para hacer los viajes, eso lo resolvía la seccional. Pero a nivel nacional para hacer marchas y todas esas cosas, se salían de los congresos, que se hacían una vez en cada lugar. A veces se hacía en Córdoba, Rosario, Tucumán".
}

Por citar algunos ejemplos que fueron hallados en los documentos consultados, el 4 de junio de 1972 se realizó en Córdoba el Congreso de la Comisiones de Familiares de Presos Políticos, estudiantiles y gremiales organizado por la COFAPPEG. En el mismo, se resolvió realizar una semana de protesta del 2 al 9 de julio y convocar a todas las organizaciones populares solidarias con los presos políticos a discutir la organización de un Congreso Nacional de Solidaridad. ${ }^{30}$

Finalmente, quiero destacar la realización de una reunión el 30 de mayo de 1972 en el Hotel Savoy de la Capital Federal promovida por el Movimiento Nacional Justicialista y el Encuentro Nacional de los Argentinos (ENA) para exigir la inmediata libertad de los presos políticos, gremiales, estudiantiles y conexos. Aunque allí no quedó registrada la participación de COFAPPEG, sí se mencionan "Comisiones de Rosario y Córdoba” ${ }^{31}$ y es posible que la referencia aludiera a las COFAPPEG de ambas ciudades.

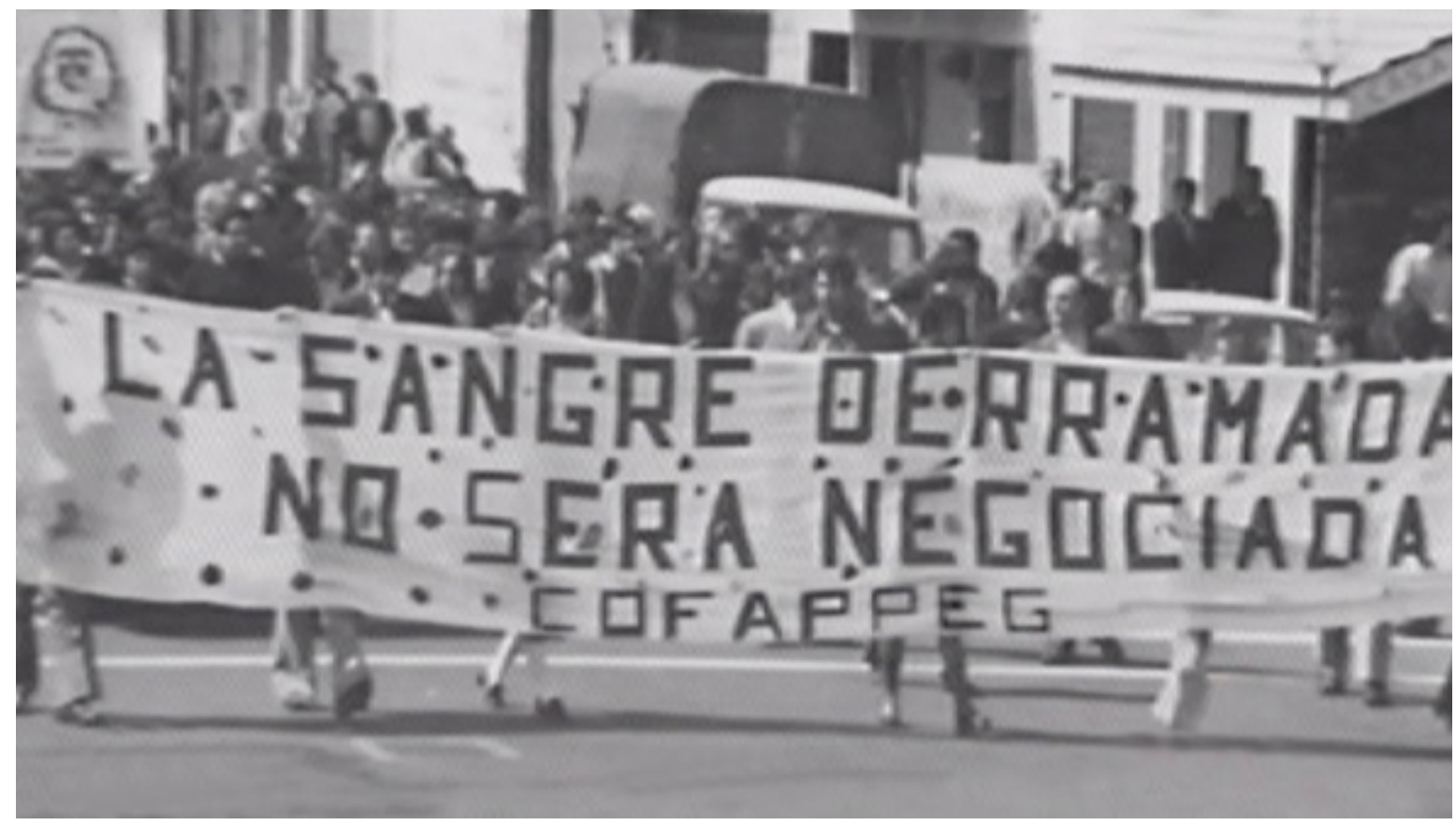

Foto gentileza de Rubén Suarez

Las tareas de defensa no fueron realizadas sólo por familiares o abogados fuera de las cárceles sino que los propios presos políticos se organizaron dentro de estas y desarrollaron acciones de lucha y resistencia a las condiciones que les imponía el sistema penitenciario. Una práctica característica del periodo fueron las huelgas de hambre -y los apoyos externos- llevadas a cabo fuera o dentro de los penales. También los 
familiares y otros grupos de apoyo realizaron huelgas de hambre fuera de las cárceles o en espacios públicos. Como sostienen numerosos testimonios de ex presos y militantes, esta práctica era característica de los presos integrantes del PRT-ERP ${ }^{32}$ y, por tanto, también fue un repertorio de acción utilizado por la COFAPPEG.

Diciembre siempre fue un mes crítico para los familiares de los represaliados. Por un lado, por el advenimiento de las fiestas de Navidad y fin de año, de gran importancia en la cultura argentina. Pero además, por la inminencia de la larga feria judicial del mes de enero, que suspende cualquier tipo de trámite en ese sentido. Por eso, diciembre fue el mes elegido por los familiares y allegados de los presos políticos para realizar las peticiones a fin de lograr la libertad de sus seres queridos o, en todo caso, mejorar las condiciones de reclusión. Complementariamente, también fue el momento de iniciar las huelgas de hambre.

En Rosario, el 20 de diciembre de 1971, la COFAPPEG realizó una conferencia de prensa para dar a conocer la situación en que se encontraban los presos políticos y anunció el inicio de una huelga de hambre en las cárceles de todo el país, denunciando que a raíz de esta medida “(...) se reprimió a los detenidos cortándosele el suministro de agua". ${ }^{33}$ Se solicitó al Colegio de Abogados y a la Comisión de Defensa de los Derechos Constitucionales y Libre Ejercicios de la profesión, el asesoramiento y pronunciamiento ante los hechos denunciados reclamándose asimismo el apoyo de todas las entidades. También se informó que desde el lunes 20 los detenidos cuyos familiares integraban la mencionada Comisión, habían iniciado un ayuno para lograr una amnistía ante las próximas fiestas de Navidad y Año Nuevo. Por último, se dio a conocer la lista de las personas que se encontraban detenidas en Rosario, alojados los varones en la cárcel de Encausados y las mujeres en la Policía Federal.

Aun así, la mayor huelga de hambre se dio como respuesta al reglamento para detenidos de máxima peligrosidad, sancionado el 3 de octubre de 1972, mediante la Ley 19.863. Este reglamento era una de las consecuencias de la fuga de Rawson. Su pretensión era centralizar disposiciones, leyes, reglamentos y resoluciones, elaborando un régimen único y diferente del de los procesados y presos comunes. El mismo se aplicó en Rawson, Villa Devoto, el buque Granadero y el penal de Villa Urquiza, ubicado en la provincia de Tucumán. ${ }^{34}$ A esto se le sumó la decisión del 20 de diciembre de sancionar la Ley 20.032 que facultaba al Poder Ejecutivo a emplear a las Fuerzas Armadas (FFAA) en el territorio argentino para prevenir y combatir la subversión interna, el terrorismo y demás hechos conexos (Eliaschev, 2011).

Iniciada entre el 19 y el 20 de diciembre de 1972 por los presos políticos de todo el país, la huelga de hambre comenzó bajo el lema "Por una Navidad y Año Nuevo sin presos políticos" y se realizó a nivel nacional (Eidelman, 2010).

En respuesta a la huelga, el 9 de enero de 1973 el gobierno nacional modificó los artículos 25 y 32 del reglamento para detenidos de máxima peligrosidad, aumentando el número de recreos y estableciendo que los abogados defensores debían presentar una certificación en la que constase su condición de tales para entrevistarse con ellos (Eliaschev, 2011). Debido a esto, la huelga se levantó el 10 de enero de 1973, luego de 17 días de ayuno.

No obstante, el reclamo continuó. El 17 de enero en una reunión convocada por la Comisión de Familiares de Presos Políticos en Santa Fe, distintas organizaciones informaron sobre la situación en la que vivían los detenidos en Rawson, Devoto y Buque Granadero, manifestando que “(...) el decreto presidencial del 10 del corriente es una burla ya que no soluciona en lo más mínimo las condiciones existentes y solamente concede 6 recreos semanales de una hora en lugar de 3". "También coincidieron en exigir la inmediata derogación de la Ley 19.863 del reglamento. Al mismo tiempo, aparecía el reclamo por una ley de amnistía que permitiera la liberación de los presos políticos.

En febrero de 1973, se dio a conocer un acta de "compromiso" que intentaba mantener la influencia de las FFAA en el poder, ya que entendían que el próximo gobierno sería de "transición". De los cinco puntos del acta, el cuarto establecía: "Descartar la aplicación de amnistías indiscriminadas para quienes se encuentren bajo proceso o condenados por la comisión de delitos vinculados con la subversión y el terrorismo". ${ }^{36}$ En 
respuesta, la COFAPPEG se abocó a la organización de un acto en reclamo de una ley de amnistía. Por ello, el Partido Socialista de los Trabajadores (PST) le envió una carta donde adhería a la movilización convocada por esta organización, al tiempo que fijaba posiciones, críticas y disidencias. Es a partir de esas críticas que se pueden vislumbrar las estrategias que llevaba a cabo la COFAPPEG así como también los vínculos con dirigentes, especialmente gremiales, que sostenía. En ella, el PST la acusaba de utilizar el reclamo por los presos para realizar "especulación política", "calculo sectario" y "acción de propaganda" y le reclamaba la necesidad de realizar "una gran movilización popular" y "un acto masivo", sosteniendo que sería mejor comprometer a todos los partidos políticos que "hacer un acto con los mimos oradores y los mismos concurrentes" ${ }^{37} \mathrm{Se}$ refería a Raimundo Óngaro y los curas tercermundistas, por el sector peronista, y a Agustín Tosco y René Salamanca, por el sindicalismo combativo, invitados por la Comisión para dicho acto. En comparación, el PST sostenía necesario invitar a todos los candidatos presidenciales, tanto a Héctor Cámpora como a Ricardo Balbín, y a otros gremialistas, como Luis Gómez, dirigente del “Somisazo”, y José Páez, dirigente de SITRAC. Más allá de las particularidades y los nombres propios, la carta demuestra una diferencia de opiniones dentro de la izquierda sobre cómo llevar a cabo la lucha por la libertad de los presos políticos y, aunque tal vez de un sector minoritario, una fuerte crítica a la COFAPPEG.

En el periodo que abarca desde la realización de las elecciones hasta la asunción del nuevo gobierno y las primeras medidas de este (marzo-mayo de 1973), muchas organizaciones continuaron denunciando la situación de los presos políticos, al tiempo que exigían por indulto y amnistía para ellos. Asimismo se pedía la derogación de la legislación represiva y la conformación de comisiones para investigar las violencias sufridas. ${ }^{38}$

Todo este conjunto de actividades da cuenta del trabajo realizado en pos de la liberación de los presos políticos en todo el país. De esta forma se evidencia que la amnistía decretada cuando asumió el gobierno democrático fue el resultado de la solidaridad y movilización popular impulsadas por estas comisiones en apoyo a los detenidos políticos.

\section{El Devotazo}

En 1972, el gobierno del general Alejandro Agustín Lanusse se vio en la obligación de convocar a elecciones para el año siguiente. El 11 de marzo de 1973, Héctor Cámpora fue el candidato más votado, pero no superó el 50\% que exigía la legislación vigente. Por esa razón correspondía realizarse una segunda vuelta con Ricardo Balbín, quien decidió no presentarse en el balotaje, razón por la cual Cámpora fue proclamado presidente. Asumió el 25 de mayo de 1973.

Finalizada la ceremonia de asunción, una enorme manifestación se dirigió a la cárcel de Devoto, para liberar a los presos políticos que estaban alojados allí, desencadenando una pueblada que se ha conocido como el "Devotazo", aunque lo mismo sucedía en otras cárceles del país. En la madrugada del 26 de mayo, por la presión de la movilización popular, Cámpora dictó el Decreto 11/1973 disponiendo el indulto de 372 personas, si bien se estima que fueron liberados unos 450 presos políticos. ${ }^{39} \mathrm{El}$ PEN dejó en libertad a 50 presos sin proceso y los gobernadores de Córdoba y Santa Fe indultaron 47 personas más. Primero dictaron el Indulto pero después se les exigió la Ley de Amnistía porque en realidad el Indulto suprime la pena pero no el delito, entonces los ex presos quedaban con ese antecedente.

Además de todo el trabajo realizado en pos de la liberación de los presos políticos de los años previos, la COFAPPEG tuvo una importante participación en la manifestación por la amnistía del 25 de mayo de 1973. Diversos testimonios de ex militantes del PRT recordaban, por un lado, la concentración junto a la COFAPPEG en la Plaza de Mayo mientras aguardaban la liberación (De Santis, 2010, p. 322) y, por otro, la reunión en el local de la COFAPPEG luego de producida aquella, donde entre otras tareas buscaron una ubicación segura para los compañeros que habían sido recientemente liberados. Pedro Cazes Camarero sostuvo que: “(...) nos fuimos a la sede de la COFAPPEG. Y ahí, por si acaso, porque éramos muy conscientes 
de que no había una lista de indulto, y que era factible que se arrepintieran, entramos a distribuir a los compañeros en casas de simpatizantes que no fueran familiares" (citado en De Santis, 2010, p. 332).

La concentración y la reunión en el local de la COFAPPEG de militantes y presos del PRT demuestran tanto la afinidad de ambas organizaciones como la importancia de la COFAPPEG en el proceso que finalmente culminó con la amnistía de los presos, a partir del trabajo político que venían desarrollando en la denuncia de las condiciones carcelarias y por la liberación de los detenidos.

\section{LA CONTINUIDAD Y/O AGOTAMIENTO DE LAS AGRUPACIONES DEFENSISTAS EN EL GOBIERNO PERONISTA}

Con el retorno de la democracia luego de siete años de dictadura militar y la amnistía del 25 de mayo de 1973, se produjo un intenso debate al interior de las agrupaciones de abogados y de los organismos defensistas. La discusión giraba en torno a qué posición debían tomar frente a la instauración del Estado de derecho y a un nuevo gobierno elegido a través de elecciones democráticas. Lo que, en parte, traducía el debate que se daba al interior de las organizaciones político-militares acerca de si era pertinente continuar la lucha armada bajo un gobierno democrático. ${ }^{40} \mathrm{El}$ debate consistía en si los abogados debían tomar o no a su cargo la defensa de los imputados en acciones armadas durante el nuevo gobierno. Más aún, si los detenidos que hubieran cometido actos de este tipo debían seguir siendo considerados como presos políticos. "Para algunos, que pusieran en riesgo los intereses de un gobierno democráticamente elegido los posicionaba fuera de los que hasta entonces se habían considerado presos políticos. Para otros, esta categoría estaba determinada más por los objetivos y los móviles que por las prácticas o los efectos de los actos" (Bacci, Carnovale y Oberti, 2010, p. 26).

Las circunstancias comenzaron a cambiar a los pocos meses de asumido el nuevo gobierno de Héctor Cámpora. Las tensiones acumuladas salieron a la luz el día del retorno definitivo de Perón a Argentina, donde se hizo visible el conflicto que había entre las organizaciones de izquierda y la derecha peronista desde la masacre de Ezeiza, ocurrida en junio de 1973. A partir de la muerte de Perón, el $1^{\circ}$ de julio de 1974 , comenzó un verdadero espiral de violencia que se desplegó aún con más fuerza. Los presos políticos volvieron a llenar las cárceles del país, incluso los peronistas. Algunos abogados comprometidos siguieron siendo asesores legales de sindicatos, otros de partidos políticos u organizaciones armadas y otros atendiendo casos individuales, pero a medida que aumentaba la represión crecía también la persecución sobre ellos.

La COFAPPEG funcionó como tal hasta mayo de 1973 con la amnistía a los presos políticos en el "Devotazo”. Según Eidelman, “(...) tras la liberación de los presos y luego de un tiempo dedicado a tareas residuales, como ayudar a conseguir trabajo a algunos de los amnistiados, la COFAPPEG se desarticuló, por pocos meses, y los militantes de PRT que activaban en su interior fueron reasignados a diferentes frentes" (2009, p. 32). Siguiendo al autor, luego del asalto al Comando de Sanidad del Ejército por parte del PRT-ERP en setiembre de 1973, la COFAPPEG fue restablecida y tuvo una fuerte actividad entre 1973 y 1976, hasta que fue disuelta durante la última dictadura militar, en junio de 1976, por el decreto ley 23.325. ${ }^{41}$ Lo mismo sostiene Cristina Rodríguez: “Cuando viene la amnistía, el 25 de mayo, a los pocos días se desarma la COFAPPEG, ya no tenía sentido. Pero ya en septiembre, cuando caen ellos por Sanidad, ahí vuelve a formarse la Comisión de Familiares" ${ }^{42}$ Su compañero, Rubén Suárez, fue uno de los combatientes que participó en el copamiento de Sanidad y fue nuevamente apresado.

Entre finales de 1973 y comienzos de 1974, la COFAPPEG comenzó a publicar boletines mensuales o bimensuales denominados Boletín de Información, ${ }^{43}$ los que dan cuenta de su continuidad por estos años, aunque ahora resaltaban su adhesión al Movimiento Nacional de Solidaridad con los Presos Políticos (MNSPP), como explicaré en el próximo apartado. En los dos números a los que he podido acceder de estos boletines se reseñaban los nuevos detenidos y los episodios de represión, no solo política sino también de violencia policial, denunciando asesinatos a sangre fría por "error" o sobre diversas manifestaciones; se 
criticaban la reforma del Código Penal, las leyes de Asociaciones Profesionales ${ }^{44}$ y de Prescindibilidad; ${ }^{45}$ se resaltaba la preocupación sobre hechos de la "realidad nacional", como la mortalidad infantil; se enumeraban las cesantías y paros de los trabajadores; se publicaban cartas de los presos de diferentes cárceles del país; se repudiaban la dictadura de Pinochet en Chile y el golpe de Estado en Uruguay; etc.

Párrafo aparte merece una nueva alusión a las huelgas de hambre. El Boletín de marzo de 1974 comenzaba con una Editorial titulada: "Huelga de hambre. Única arma de lucha de los prisioneros", donde se argumentaba sobre la necesidad de esta medida, y reproducía un Comunicado con el texto de la Conferencia de Prensa realizada el 24 de ese mes por la COFAPPEG que notificaba que desde el 22 los presos de la cárcel de Caseros iniciaron una huelga de hambre motivada por el arbitrario traslado desde Devoto y el "apaleamiento del que fueron objeto los detenidos" que se opusieron a tal medida. Los familiares anunciaban el apoyo desde afuera y enumeraban la lista de reclamos, que abarcaban desde el cese a los apremios generales hasta el retiro de determinados oficiales responsables de hechos puntuales y el levantamiento de la pena a trece detenidos en las celdas de castigo. ${ }^{46}$

Boletin de Información de COFAPPEG, Año 1, N³ (marzo 1974): 3.
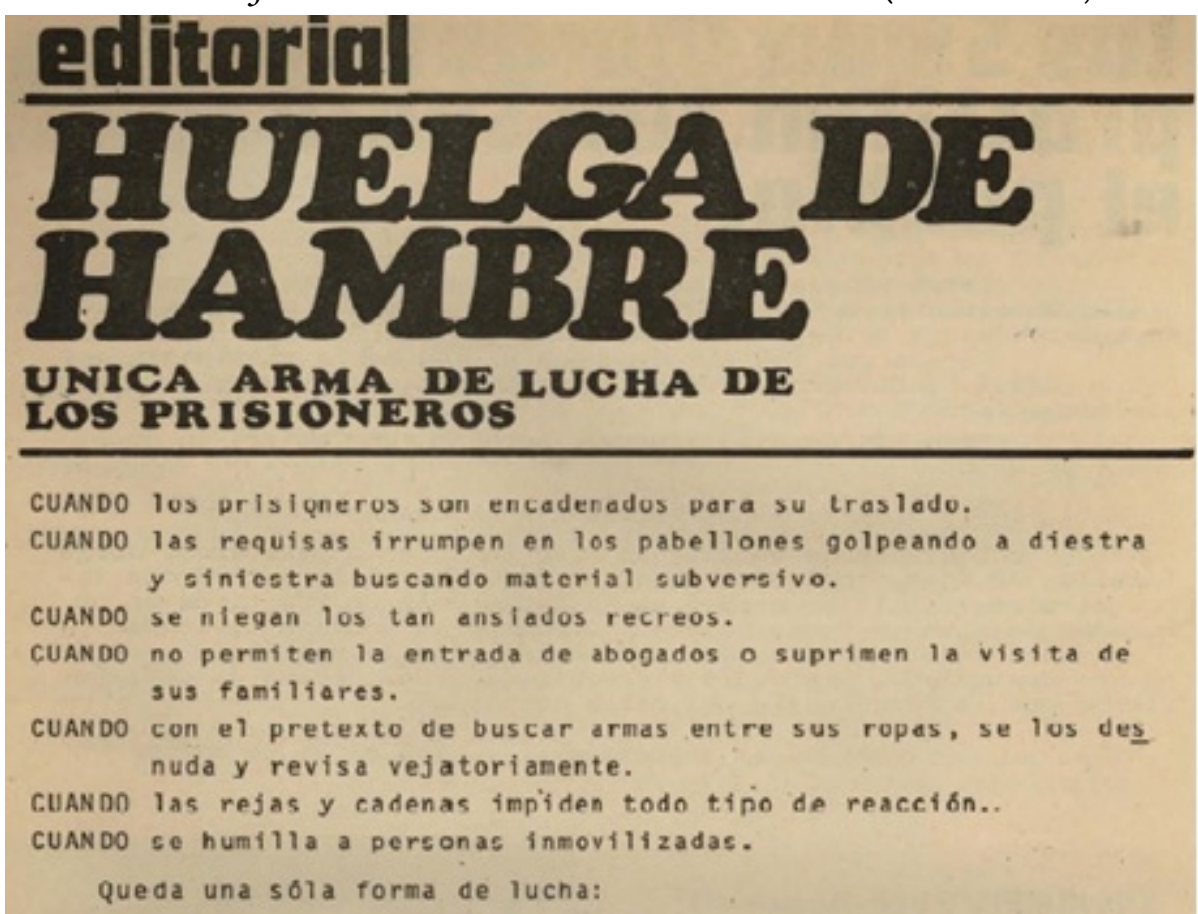
Boletín de Información de COFAPPEG, Año 1, ํ 4 (mayo 1974): 29.

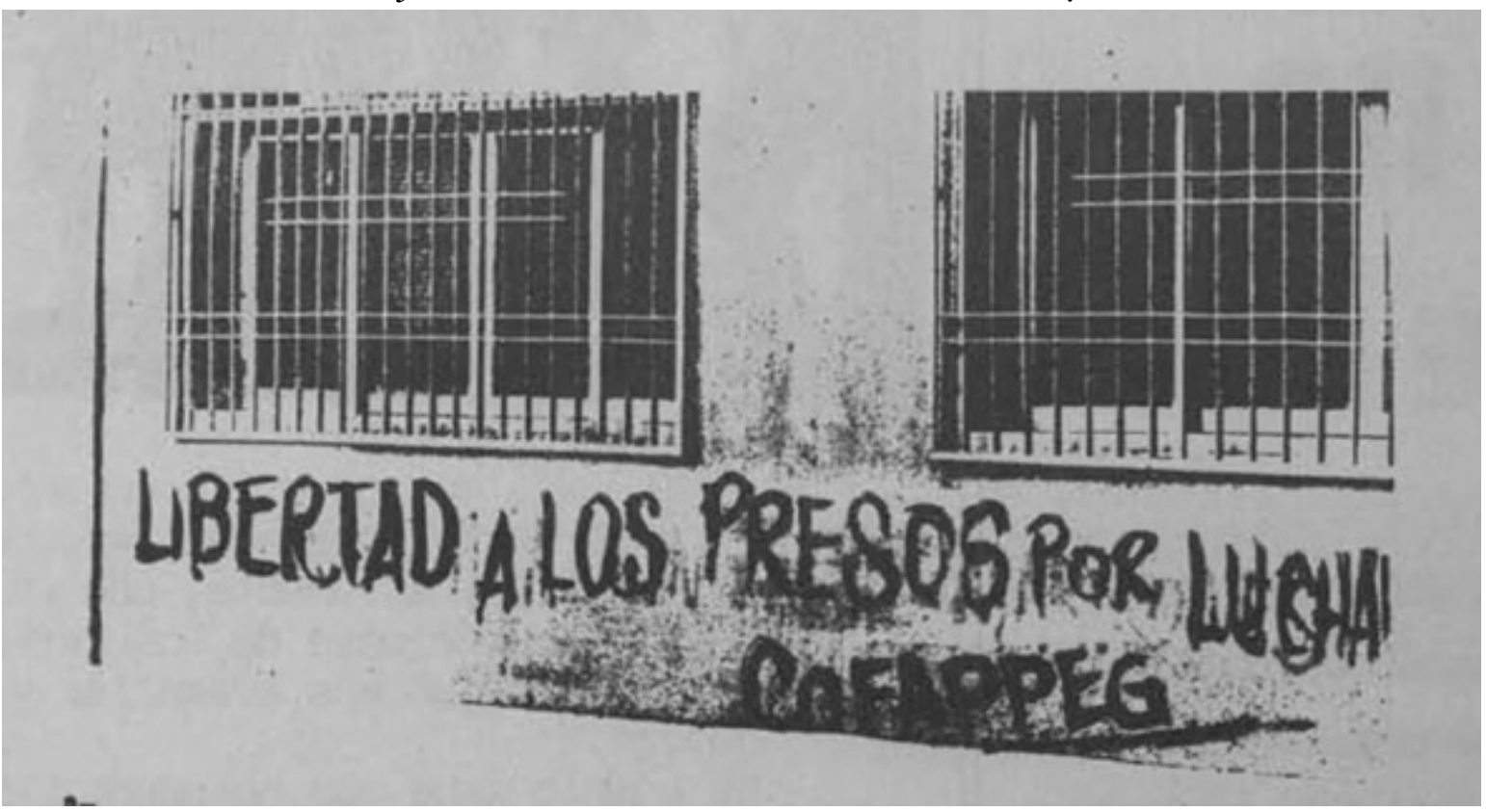

En mayo de 1974, según el Boletín $N^{\circ}$ 4, seis familiares de presos políticos integrantes de la COFAPPEG fueron detenidos en Buenos Aires por realizar pintadas en pos de la liberación de los presos, al tiempo que esta Comisión publicaba una solicitada con la misma consigna: "A un año del Devotazo: Libertad a los Presos políticos". 47

\section{El Movimiento Nacional de Solidaridad con los Presos Políticos (MNSPP)}

En el contexto de la huelga de hambre de diciembre de 1972 apareció otro agrupamiento: el Movimiento Nacional de Solidaridad con los Presos Políticos, Estudiantiles y Gremiales (MNSPP). ${ }^{48}$ En ciertos documentos consultados de la provincia de Santa Fe, este agrupamiento es mencionado con la palabra Comisión, pero por la similitud de sus nominaciones parece ser el mismo: Comisión de Solidaridad con los Presos Políticos, Estudiantiles y Gremiales o Movimiento Nacional de Solidaridad con los Presos Políticos, Estudiantiles y Gremiales, nominaciones que en ocasiones eran acompañadas por la aclaración de "Regional Santa Fe". En Córdoba también hizo su aparición este Movimiento en el mismo contexto, así lo presentó Mónica Gordillo: “(...) diferentes grupos se habían conformado para la denuncia y defensa de los detenidos. Así, (...) encontramos un nuevo agrupamiento: 'Movimiento Nacional de Solidaridad con los presos políticos'. El mismo promovió una huelga de Hambre a fines de 1972” (2001, p. 57). En mayo de 1973, en una suerte de volante o solicitada que el MNSPP distribuyó, ${ }^{49}$ se mencionaban las Regionales firmantes entre las cuales se encontraban Tucumán, Santiago del Estero, La Rioja, Córdoba, Villa María, Paraná, Santa Fe, Rosario, ${ }^{50}$ Buenos Aires, Concepción del Uruguay, La Plata y Trelew. 
Afiche del Movimiento Nacional de Solidaridad con los Presos Políticos, Estudiantiles y Gremiales, Regional Santa Fe, enero de 1973. Caja 39, APMSF

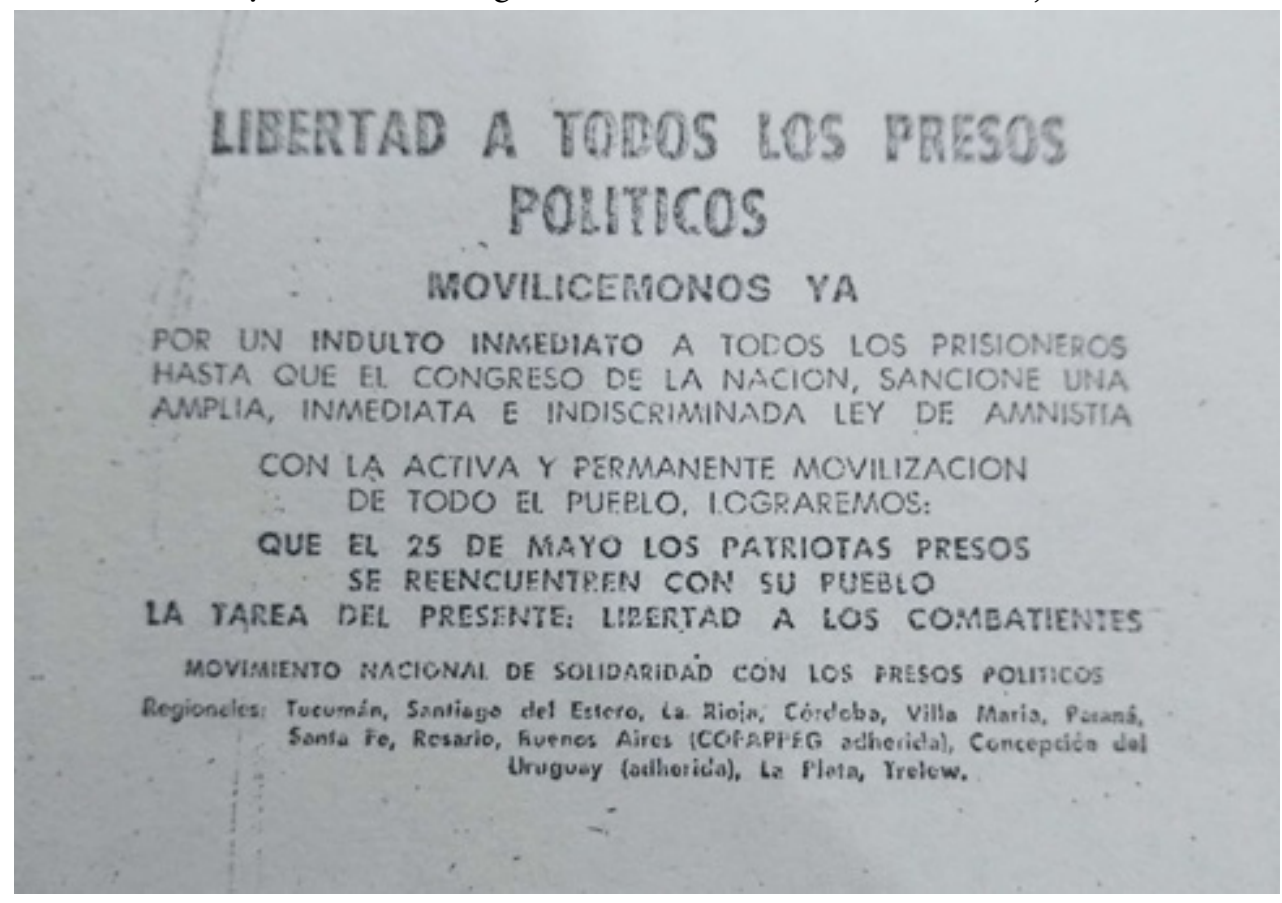

Entiendo que este Movimiento era el formado en zona de Puerto Madryn, Rawson y Trelew, donde a partir del comienzo de la llegada de presos políticos a la cárcel de Rawson desde junio de 1971, se crearon distintas comisiones de solidaridad. ${ }^{51}$ Estas comisiones confluyeron en lo que fue conocido como el "Trewelazo" cuando, tras el "operativo vigilante" que culminó con la detención y traslado a Buenos Aires de 16 personas, se creó una suerte de asamblea que funcionó hasta la liberación del último detenido, Mario Abel Amaya, ${ }^{52}$ que se encontraba encarcelado con anterioridad a este operativo pero fue incluido en los reclamos de la asamblea.

Cristina Rodríguez también menciona a este agrupamiento: "En Rawson, nace el Movimiento Nacional de Solidaridad con los Presos Políticos, el MSPP, ${ }^{53}$ que estaba Ángel Bel, ${ }^{54}$ Mario Abel Amaya, (...) [la pareja de] los Beltrán Mulhall, ${ }^{55}$ de allá de Trelew que organizaron toda la movida para ir a ver allá a los presos". ${ }^{56}$ Según ella, este Movimiento también tenía vínculos con el PRT y tuvo continuidad incluso después de la amnistía de 1973. La única referencia de la época donde encuentro una sigla para este movimiento, ${ }^{57} \mathrm{MNSPP}$, es la revista Posición, donde se sostiene que "El miércoles 18 de abril integrantes de la coordinadora de lucha por la amnistía entre quienes se encuentran: la Comisión de Familiares de presos políticos, estudiantiles y gremiales COFAPPEG, (...) Movimiento Nacional de Solidaridad con los Presos Políticos (MNSPP) (...) realizaron un acto a las 20 horas, frente al local de la CGT".58

Lo que efectivamente podemos comprobar es que, al menos desde el año 1974, la COFAPPEG adhirió formalmente a este Movimiento, tal cual lo enunciaban en los boletines que comenzaron a editar por entonces, donde en su portada se presentaban como: COFAPPEG Comisión Familiares Politicos, Estudiantiles y Gremiales, adherido al Movimiento Nacional de Solidaridad. ${ }^{59}$ Estos boletines además confirman el surgimiento del MNSPP en la zona de Trelew, cuando en uno de sus números sostienen que: "Trelew y Rawson fueron ciudades amigas, porque sus habitantes, su pueblo, sus trabajadores, sus estudiantes, sus profesionales a través del Movimiento Nacional de Solidaridad con los Presos Políticos nos albergaban, protegían y ayudaban". ${ }^{60}$

El Movimiento Nacional de Solidaridad siguió apareciendo en los partes policiales de la provincia de Santa Fe al menos hasta mayo de 1975, aunque en esta nueva etapa, ya no aparece acompañado de las 
adjetivaciones de "Políticos, Estudiantiles y Gremiales" -tan propias del periodo anterior--, ni reviste el carácter de "Nacional". Por esto último, tampoco lleva la aclaración de "Regional Santa Fe". En todo caso, puede pensarse como una reactivación de aquel MNSPP pero con diferentes denominaciones y no parece estar constituido por los mismos integrantes, ya que para este momento todos ellos eran familiares de presos detenidos a partir de 1974, con excepción de Cristina que también participa en esta etapa.

\section{A MODO DE CIERRE}

Esta reconstrucción intenta determinar el derrotero de una de las comisiones más significativas de familiares de presos políticos surgida a principios de los años 70: la COFAPPEG. Pese a que la información disponible es escasa y fragmentaria, he podido establecer su constitución y desarrollo; las continuidades existentes entre el periodo de la dictadura militar (1966-1973) y gobierno democrático (1973-1976) y las vinculaciones tanto de la COFAPPEG con el PRT-ERP como con el MNSPP y otras comisiones dedicadas a la misma tarea.

Al mismo tiempo, destaco todo el trabajo realizado, sus posicionamientos y repertorios de acción, no solo en apoyo y solidaridad con los presos políticos, sino también y fundamentalmente en pos de su liberación en todo el país, hasta llegar a la amnistía como resultado de la solidaridad y movilización popular impulsadas, junto a otras, por esta Comisión. A partir de allí su continuidad es esporádica y su derrotero desaparece junto al avance de la represión del gobierno democrático.

Por esta razón, aunque la COFAPPEG fue declarada disuelta o ilegal por la Junta Militar en junio de 1976, el rastro de esta Comisión se pierde ya para el año 1974 y el MNSPP apareció en Santa Fe sólo hasta mayo de 1975. Esto sugiere que pese a la reactivación de estas comisiones para finales del año 1973, con la intensificación y el cambio de modalidad en la represión, que aísla cada vez más a las organizaciones de representación como los partidos políticos y los sindicatos, estos agrupamientos también se vieron afectados por la represión y el aislamiento y paulatinamente se desintegraron, al menos como se los conocía bajo determinadas denominaciones y formas de organización.

\section{REFERENCIAS}

Alonso, L. (2011). Luchas en plazas vacias de sueños. Movimiento de derechos humanos, orden local y acción antisistémica en Santa Fe. Rosario: Prohistoria Ediciones.

Águila, G. (2017). El accionar represivo entre dos dictaduras, 1966-1983. En Águila; Almada, L.; Divinzenso, M. A. y Scocco, M. Territorio Ocupado. La historia del Comando del II Cuerpo de Ejército en Rosario (1960-1990) (pp. 99-206). Rosario: Editorial de la Municipalidad de Rosario.

Bacci, C., Carnovale, V.y Oberti, A. (2010). Abogados, Derecho y Política. Buenos Aires: Memoria Abierta. Recuperado de http://memoriaabierta.org.ar/wp/wp-content/uploads/2018/07/Abogados-derecho-y-politica.pdf.

Bereciartúa, L. (2013). Abogados y defensas politicas 1968-1973 (Tesina de Licenciatura inédita). Facultad de Humanidades y Artes, Universidad Nacional de Rosario, Rosario, Argentina.

Brufman, G. (21 de agosto de 2016). El maestro Bel, la masacre de Trelew y las paradojas de la memoria. Prensa CTA Santa Fe.

Carnovale, V. (2011). Los combatientes. Historia del PRT-ERP. Buenos Aires: Siglo XXI.

Carminati, A. (2017). Los trabajadores del cordón industrial del Gran Rosario ante la dictadura militar (1976-1983) (Tesis doctoral inédita). Facultad de Humanidades y Artes, Universidad Nacional de Rosario, Rosario, Argentina.

Carreras, J. (15 de enero de 2013). Revista Posición. Blog Luz de agosto. Recuperado de http://fulgor.blogspirit.com/ archive/2013/01/15/revista-posicion.html.

Chama, M. (2016). Compromiso politico y labor profesional. Estudios sobre psicólogos y abogados en los primeros setenta. La Plata: Universidad Nacional de La Plata. Facultad de Humanidades y Ciencias de la Educación. 
Chama, M. (2014). Activismo social, militancia política y radicalización de los años sesenta. La experiencia de la Comisión de Familiares de Detenidos (COFADE). En Tortti, M. C. (dir.) La nueva izquierda argentina (1955-1976). Socialismo, peronismo y revolución. Rosario: Prohistoria Ediciones.

Chama, M. (2010). La defensa de presos políticos a comienzos de los '70: ejercicio profesional, derecho y política. Cuadernos de antropología social, (32).

D’Antonio, D. y Eidelman, A. (2018). Poder judicial, represión y violencia política en los setenta: la experiencia del 'Camarón'. En D'Antonio, D. Violencia, espionaje y represión estatal. Seis estudios de caso sobre el pasado reciente argentino. Buenos Aires: Imago Mundi.

De Santis, D. (2010). La Historia del PRT-ERP pos sus protagonistas. Temperley: Estación Finlandia.

De Santis, D. (2004). iA vencer o morir! PRT-ERP Documentos (Tomo 2). Buenos Aires: Eudeba.

Eidelman, A. (2010). El buque-cárcel Granadero y los presos políticos, 1972-1973. VI Jornadas de Sociología de la UNLP, La Plata, Argentina.

Eidelman, A. (2009). El PRT-ERP y la lucha por la libertad de los presos políticos, 1971-1973. Sociohistórica, (25), 13-39.

Eliaschev, P. (2011). Los hombres del juicio. Buenos Aires: Sudamericana.

Fernández Picolo, M. (2014). Los presos políticos en Rawson y la solidaridad. En VV.AA. Trelew. Esa masacre que aún es fuego. Rawson: Secretaría de Cultura de la provincia de Chubut.

Garaño, S. (2007). El PRT también se forja en las cárceles. Lucha Armada, (9), 48-59.

Gordillo, M. (2003). Protesta, rebelión y movilización: de la resistencia a la lucha armada. En James, D. (Ed.). Violencia, proscripción y autoritarismo (1955-1976) (pp. 329-380). Buenos Aires: Editorial Sudamericana.

Gordillo, M. (2001). Actores, prácticas, discursos en la Córdoba combativa. Una aproximación a la cultura política de los '70. Córdoba: Ferreira Editor.

Kotler, R. (2014). Elpaís del síme acuerdo. Los origenes nacionales y transnacionales del movimiento de derechos humanos en Argentina: De la dictadura a la transición. Buenos Aires: Imago Mundi.

Larraquy, M. (2017). Primavera sangrienta: Argentina 1970-1973 un pais a punto de explotar. Guerrilla, presospoliticos y represión ilegal. Buenos Aires: Sudamericana.

Mattini, L. (1995). Hombres y mujeres del PRT-ERP de Tucumán a la Tablada. La Plata: Ediciones de la Campana.

Oviedo, S. y Solis, C. (2006). Violencia institucionalizada y formas de resistencia social: los organismos de Derechos Humanos en Córdoba durante la dictadura (Trabajo Final para acceder a la Licenciatura en Historia Inédito). Facultad de Filosofía y Humanidades, Universidad Nacional de Córdoba, Córdoba, Argentina.

Pasquali, L. (2011). ¿Frente legal vs. Frente militar? El desarrollo del PRT-ERP en Rosario durante la llamada “etapa militarista". Testimonios, 2(2), 17-36.

Philp, M. (2016). Memoria y politica en la Historia argentina reciente: una lectura desde Córdoba. Córdoba: Editorial de la Universidad Nacional de Córdoba.

Ponisio, M. (2016). Las leyes de prescindibilidad en los gobiernos locales de la provincia de Santa Fe durante la última dictadura (1976-1983). Antecedentes y particularidades en su aplicación a partir de un estudio de caso. Revista de Historia, (17), 202-224.

Pozzi, P. (2001). Por las sendas argentinas. El PRT-ERP. La guerrilla marxista. Buenos Aires: Eudeba.

Scocco, M. (2020). Una historia en Movimiento. Las luchas por los derechos humanos en Rosario (1968-1985). La Plata: Universidad Nacional de La Plata; Universidad Nacional de Misiones; Universidad Nacional de General Sarmiento. En prensa.

Scocco, M. (2019). De los consejos de guerra al Camarón. Respuestas represivas a las protestas sociales (1969-1973). Anuario Escuela de Historia Virtual, 10(16).

Solis, C. (2014). De las comisiones a los organismos en Córdoba: derechos humanos, dictadura y democratización. En Kotler, Rubén (Ed.). El pais del si me acuerdo. Los origenes nacionales y transnacionales del movimiento de derechos bumanos en Argentina: De la dictadura a la transición. Buenos Aires: Imago Mundi. 
Tessa, Sonia (17 de agosto de 2012). Las puertas que se van abriendo. Suplemento Las 12, Página 12. Recuperado de: https://www.pagina12.com.ar/diario/suplementos/las12/13-7442-2012-08-17.html.

Yofre, J. B. (2009). Volver a matar. Buenos Aires: Sudamericana.

\section{Notas}

1 Este artículo es la reelaboración de una ponencia presentada en las XVII Jornadas Interescuelas/Departamentos de Historia. Catamarca 2, 3, 4 y 5 de octubre de 2019.

2 Posición era una revista que salió en Córdoba, vinculada al PRT, aunque no orgánica. Agradezco esta referencia a Leandro Inchauspe. Se publicó entre los meses de diciembre de 1972 y julio de 1974, con una tirada de cinco mil ejemplares (Carreras, 2013).

3 Para mayor información sobre la represión estatal en este período ver D 'Antonio y Eidelman, 2018 y Scocco, 2019.

4 El uso de la adjetivación "defensista" para referirme a la acción de defensa que llevaron a cabo diversas personas, grupos u organizaciones, tanto en defensa de presos políticos como de los derechos humanos en general, es una categoría nativa que proviene de la defensa de presos políticos de la primera mitad de los años setenta, que en cierta forma se extendió de los abogados a las organizaciones. Es un término que procede del derecho y puede referir a los abogados defensores de cualquier litigio. En la historia argentina contemporánea existe una larga tradición defensista que comienza desde principios siglo XX.

5 Siguiendo a Chama, la organización -con una trascendencia pública de casi una década- tuvo dos grandes momentos. El primero, entre 1960-1963, motorizado por un reducido grupo de familiares que buscaron mantener un criterio de autonomía y prescindencia partidaria y, el segundo, entre 1964-1970, orientado por un núcleo de militantes identificados con una de las vertientes más combativas del peronismo, el Movimiento Revolucionario Peronista (MRP), liderado por Gustavo Rearte. El autor también resalta que aunque la sigla se mantuvo (COFADE) en sus primeros años significaba Comisión de Familiares de Detenidos, luego Comisión de Familiares de Detenidos Políticos y Gremiales, para finalmente transformarse en Comisión de Familiares y Amigos de Detenidos. Para mayor información sobre COFADE ver Chama, 2014.

6 COFAPPEG, Torturas en Argentina, Córdoba, julio de 1972, última página. La mayúscula es del original.

7 El PRT se fundó el 25 de mayo de 1965 en Buenos Aires a partir de la fusión de dos agrupaciones políticas: el Frente Revolucionario Indoamericano Popular (FRIP) y Palabra Obrera (PO). Creado en 1970, el ERP era el brazo armado del PRT. Hasta el año 1973 fue la principal organización guerrillera del país, por su capacidad operativa y la intensidad de su actividad de propaganda armada. Aunque la bibliografía disponible es mucho más vasta, aquí solo indico algunas referencias: Carnovale, 2011; Pasquali, 2011; De Santis, 2004 y 2010; Garaño, 2007; Pozzi, 2001 y Mattini, 1995.

8 Recién en 1975, encuentro instituidos a los frentes legales del PRT en documentos internos. En las resoluciones del Comité Central se resolvió una reforma a estatutos donde, en su Artículo 10, se estipulaba que: "Existen distintos tipos de células: a) de masas; b) militares; c) de propaganda; d) sindicales; e) legales; f) de solidaridad; g) de organización; h) de educación; i) de aparato". "Comité Central Ampliado 'Vietnam Liberado", El Combatiente No 175, 30 julio de 1975, en De Santis, 2004, p. 323.

9 Fuerzas Armadas Peronistas (FAP), Fuerzas Armadas de Liberación (FAL) y Fuerzas Armadas Revolucionarias (FAR).

10 Según Larraquy hubo un enfrentamiento, sin muertos, y 16 militantes del PRT resultaron detenidos (Larraquy, 2017).

11 Entrevista a Cristina Rodríguez y Rubén "Zurdo" Suárez, Rosario, 7 de abril de 2018, realizada por Marianela Scocco y Gustavo Brufman.

12 Entrevista a Cristina Rodríguez y Rubén "Zurdo" Suárez, Rosario, 7 de abril de 2018, realizada por Marianela Scocco y Gustavo Brufman.

13 "Porque los milicos en la cárcel nos diferencias así. Por ejemplo en Rawson estaban todos los sindicalistas que habían caído con Tosco, tanto telefónicos, como un montón de compañeros, SITRAC-SITRAM, etc., y todos esos estaban en un pabellón aparte, divido de los presos políticos, entonces trataban de dar esa clasificación. Distinta a la que se dio después, con la última dictadura, que ya directamente era entre recuperables e irrecuperables". Entrevista a Cristina Rodríguez y Rubén "Zurdo" Suárez, Rosario, 7 de abril de 2018, realizada por Marianela Scocco y Gustavo Brufman.

14 "Protesta de presos políticos", diario La Tribuna, 21 de diciembre de 1971 y "Solicitase apoyo solidario a los presos políticos", diario Crónica, 21 de diciembre de 1971.

15 Liliana Montanaro era la esposa de Osvaldo "el Tordo" De Benedetti. En 1972 ambos fueron detenidos y posteriormente liberados con la amnistía de 1973. En septiembre de 1974, el Tordo fue detenido en Tucumán y asesinado el 21 de julio de 1978, con la intención de hacerlo pasar como una fuga. 
16 Mario "Negro" Aguirre fue un importante dirigente gremial de Rosario. A partir de 1959 fue Secretario Adjunto de la Seccional ATE Rosario y en 1960 ocupó el cargo de Secretario Administrativo de la CGT Delegación Rosario, participando en 1968 de la CGTA. Falleció el 23 de agosto de 2010.

17 Entrevista a Cristina Rodríguez y Rubén “Zurdo” Suárez, Rosario, 7 de abril de 2018, realizada por Marianela Scocco y Gustavo Brufman.

18 Horas después de la detención Segundo T. Gómez fue asesinado en un enfrentamiento fraguando por la policía.

19 El Partido Socialista de los Trabajadores (PST) fue un partido político argentino fundado por Nahuel Moreno en 1972, de orientación trotskista, y surgido de la fusión del PRT La Verdad (una de las partes en que se escindió el PRT en 1968) y el grupo proveniente del Partido Socialista, liderado por Juan Carlos Coral.

20 Entrevista a Cristina Rodríguez y Rubén “Zurdo” Suárez, Rosario, 7 de abril de 2018, realizada por Marianela Scocco y Gustavo Brufman.

21 En junio de 1971 surgió a nivel nacional el Movimiento Nacional contra la Represión y la Tortura. Para Eidelman (2009) puede ser considerado, en alguna medida, como un precedente de COFAPPEG. En Rosario funcionó desde finales de ese año. Aparecen noticias de su desempeño al menos hasta agosto de 1973 cuando emitió un comunicado proponiendo la investigación de masacres, torturas y asesinatos (Parte quincenal de la Policía de Santa Fe, 15 de agosto de 1973. Caja 53B. APMSF). En Córdoba, según Philp (2016), el Movimiento Nacional contra la Represión y la Tortura luego de 1973 se denominó Comisión de Familiares de Presos Políticos, Estudiantiles y Gremiales (COFAPPEG). Pero el informe Torturas en Argentina de ésta última, publicado en julio de 1972, demuestra su existencia con anterioridad. La vinculación de ambas organizaciones al PRT-ERP pueden explicar la confusión.

22 La Comisión de Apoyo a los Presos Políticos y Gremiales o Comisión de Familiares de Presos Políticos -según las distintas versiones- se creó en noviembre de 1971 en Rosario en el estudio jurídico de Juan Bernardo Iturraspe, el padre de Francisco, también abogado e integrante de esta comisión. Un grupo de un poco más de una docena de familiares de presos políticos resolvieron su fundación. Ver "Se constituyó una comisión de apoyo a presos políticos y gremiales", diario La Opinión, 9 de noviembre de 1971 y "Presos políticos. Familiares forman una comisión”, diario La Tribuna, 15 de noviembre de 1971 . Incluía familiares de presos de diferentes organizaciones peronistas y marxistas, no obstante, por los reconocidos vínculos que tenía Juan Bernardo Iturraspe con el peronismo local y por la existencia de otras agrupaciones ligadas al PRT-ERP, se advierte que esta Comisión pudo tener una orientación más bien peronista, lo que no impidió que familiares de otras adscripciones la integraron. Entrevista a Francisco "Pancho" Iturraspe, Rosario, 13 de noviembre de 2017, realizada por Marianela Scocco.

23 Entrevista a Francisco "Pancho" Iturraspe, Rosario, 13 de noviembre de 2017, realizada por Marianela Scocco.

24 Familiares de los detenidos Cristina Planas, Manuel Navarro, Norma Garelli, Ramón Bernardo Etchegaray, Mario Delfino, Juan Carlos Alcíbar Arichuluaga, Elvira Destesano, Edén Brites, Guillermo Cittadini, Rubén Heinman, José Luis Arbel, Raúl Carliani, Hugo Campaña y Victor Lapegna. “Se constituyó una comisión de apoyo a presos políticos y gremiales", diario La Opinión, 9 de noviembre de 1971.

25 Cuando detuvieron a Del Rey, ella pasó inmediatamente a la clandestinidad y se fue a la ciudad de Santa Fe. Posteriormente fue presa política desde 1975 a 1982.

26 El 15 de agosto de 1972 se produjo la fuga de la cárcel de Rawson de un grupo de militantes y dirigentes de las organizaciones armadas Montoneros, FAR y ERP detenidos en aquella cárcel de máxima seguridad. Seis militantes lograron salir del país pero diecinueve fueron recapturados y trasladados a la base Almirante Zar de Trelew. El 22 de agosto, dieciséis de ellos fueron ejecutados, en lo que se conoce como la masacre de Trelew.

27 Como sostiene Crenzel (2008), en la historia de las luchas políticas, los funerales tras el asesinato de militantes, constituyeron momentos de reivindicación de esas muertes heroicas. Esto significa una diferencia importante con el periodo abierto después de 1976, cuando las desapariciones anularon, entre otras cosas, esos espacios públicos para homenajear a los muertos.

28 Foro de Buenos Aires por la Vigencia de los Derechos Humanos. Proceso a la explotación y a la represión en la Argentina, 1973, p. 75. Águila (2017) también resalta que el velatorio de Del Rey fue rigurosamente vigilado por fuerzas de seguridad. Al día siguiente también fue sepultado en el cementerio de Granadero Baigorria, adonde “se apersonó” el jefe de policía Feced.

29 Entrevista a Cristina Rodríguez y Rubén “Zurdo” Suárez, Rosario, 7 de abril de 2018, realizada por Marianela Scocco y Gustavo Brufman.

30 "Congreso nacional de solidaridad", revista Nuevo Hombre, junio de 1972, p. 10. Recuperado de Topo Blindado: https ://eltopoblindado.com/documentos/?s=NUEVO+HOMBRE.

31 Comisión Provincial por la Memoria (CPM) - FONDO DIPBA. División Central de Documentación, Registro y Archivo, Referencia 15.718, foja 146. Informe de la SIPBA. Asunto: Coordinadora de Lucha contra la represión. Firmado Departamento Reunión, 7 de septiembre de 1972.

32 "La huelga de hambre era una cosa que era característica de los compañeros nuestros, del PRT, de la primera dictadura, o sea del año 1971, 1970”. Entrevista a Eduardo, militante del PRT-ERP, citada en Garaño, 2007. 
33 "Solicitase apoyo solidario a los presos políticos", diario Crónica, 21 de diciembre de 1971.

34 En este reglamento se establecían pabellones específicos y divididos por sexo, se reforzaba la incomunicación y aislamiento de los presos al interior de las cárceles y se los encerraba con un régimen de celda individual cerrada en forma permanente. También se les restringió la lectura de diarios y revistas, escuchar la radio, así como la visita de los abogados defensores (Eidelman, 2010).

35 "La situación de presos políticos tratan en reunión", diario El Litoral, 17 de enero de 1973.

36 Citado en Yofre, 2009, p. 222.

37 Carta, firmada por Alberto Pujals y Ernesto González por el PST, a la COFAPPEG. 22/02/1973. Archivo digital Fundación Pluma. Recuperado de: http://fundacionpluma.info:8080/xmlui/.

38 Foro de Buenos Aires por la Vigencia de los Derechos Humanos. Proceso a la explotación y a la represión en la Argentina, 1973.

39 El listado de presos políticos indultados sumaba un total de 372 personas: 180 personas detenidas en la cárcel de Villa Devoto, 14 en Córdoba, 5 en Santa Fe, 9 en Tucumán, 2 en La Plata, 8 en la Unidad 3 de la Capital Federal y 154 personas a disposición de la Cámara Federal en lo Penal de la Nación y otros juzgados. Decreto 11/1973, N²2.699, 4 de julio de 1973, Boletín Oficial de la Nación Argentina. Recuperado de: https://www.boletinoficial.gob.ar/\#!DetalleN ormaBusquedaAvanzada/7055855/19730704. Consultado: septiembre de 2017.

$40 \mathrm{Al}$ respecto, mientras que Montoneros deponía las armas, el ERP había hecho pública su decisión de continuar con las acciones armadas contra empresas y las FFAA.

41 En junio de 1976, la Junta Militar dictó una serie de leyes que disolvían y/o declaraban ilegales numerosas organizaciones políticas, sindicales, estudiantiles, profesionales, de derechos humanos. Efectivamente en estas leyes se declaró disuelta a la COFAPPEG. Informe: "Ley 21.325. Nómina de organizaciones declaradas ilegales”, Caja 402, Legajo 3. APMSF.

42 Entrevista a Cristina Rodríguez y Rubén “Zurdo” Suárez, Rosario, 7 de abril de 2018, realizada por Marianela Scocco y Gustavo Brufman.

43 Boletín de Informaciónde COFAPPEG, Año 1, N³ (marzo 1974) y 4 (mayo 1974). Archivo digital Fundación Pluma.

44 Sancionada en diciembre de 1973. Según Andrés Carminati, con ella se pretendía blindar a las organizaciones sindicales tradicionales, que venían siendo cuestionadas por diferentes iniciativas tanto desde las bases fabriles como desde algunas regionales. En este sentido la ley ampliaba las facultades para intervenir las seccionales, anular decisiones de comités fabriles o expulsar a los activistas del sindicato por "inconducta gremial”, también extendía el mandato de los dirigentes gremiales de 2 a 4 años, entre otras cosas. Ver: Carminati, 2017.

45 Sancionada en octubre de 1973. Según Mariana Ponisio, las leyes de prescindibilidad de empleados públicos se inscriben en un continuum de legislación y prácticas previas, que se extiende desde 1966 hasta la finalización de la última dictadura militar. Ver: Ponisio, 2016.

46 Boletín de Información de COFAPPEG, Año 1, No3 (marzo 1974), p. 18. Archivo digital Fundación Pluma.

47 "A un año del Devotazo: Libertad a los Presos políticos", 22 de mayo de 1974. CPM - FONDO DIPBA División Central de Documentación, Registro y Archivo, Referencia 15.718, foja 351.

48 Ver: Afiche del Movimiento Nacional de Solidaridad con los Presos Políticos, Estudiantiles y Gremiales, Regional Santa Fe, enero de 1973. Caja 39, APMSF.

49 CPM - FONDO DIPBA. División Central de Documentación, Registro y Archivo. Referencia 15.718, foja 337.

50 Aunque en la documentación regional solo he hallado la referencia a la Regional Santa Fe.

51 Para más información ver: Fernández Picolo, 2014.

52 Mario Abel Amaya fue abogado de presos políticos y uno de los impulsores de las comisiones de solidaridad. Entre 1973 y 1976 fue diputado nacional. Fue detenido en agosto de 1976 por el V Cuerpo de Ejército con sede en Bahía Blanca, muriendo como consecuencia de las torturas a las que fue sometido.

53 Posteriormente, este Movimiento pierde el carácter de "Nacional", lo que explica que a la sigla MNSPP se le haya quitado la N y se recuerde como MSPP. Pasquali (2011) también lo denomina Movimiento de Solidaridad con los Presos Políticos (MSPP).

54 Elvio Ángel Bel era maestro y militante comunista. Había sido apoderado de la familia de Mario Roberto Santucho entre 1971 y 1972. Según Brufman (2016), Bel, junto a Mario Abel Amaya y otros dirigentes populares, impulsó y formó parte de la Comisión de Solidaridad con los Presos Políticos que se constituyó y actuó en toda la zona de Puerto Madryn, Rawson y Trelew. Fue uno de los detenidos en el "operativo vigilante". Ángel fue luego liberado, como el resto de los militantes, y regresó a Rawson, hasta que fue secuestrado por efectivos militares el 5 de noviembre de 1976 y continúa desaparecido. Entrevista a Hilda Fredes, pareja de Ángell Bel, Trelew, 11 de octubre de 2018, realizada por Marianela Scocco.

55 Él era Juez Federal radical de Rawson y ella fue una de las más activas del movimiento. Ambos fueron detenidos en el en el "operativo vigilante".

56 Entrevista a Cristina Rodríguez y Rubén “Zurdo” Suárez, Rosario, 7 de abril de 2018, realizada por Marianela Scocco y Gustavo Brufman. 
57 Otro documento donde hallo una denominación similar para el período pos-amnistía es en el discurso de Agustín Tosco de 1974: "Hablo aquí, compañeros, en nombre del Movimiento Sindical Combativo de Córdoba. Traigo el saludo fraternal de doce organizaciones sindicales, de treinta agrupaciones de base a uno de los pilares en Córdoba, del MSC, es decir al Movimiento Sindical de Base, que hoy realiza su segundo Plenario Nacional. El miércoles de la presente semana el Movimiento Sindical Combativo apoyó una conferencia de prensa de la comisión de familiares de presos políticos y sociales (...) y del Movimiento Nacional de Solidaridad, por eso compañeros es que aquí también traemos el saludo de todos los compañeros y compañeras perseguidos, represaliados, prisioneros de este gobierno por continuar con firmeza y decisión la lucha revolucionaria en defensa de los grandes ideales del pueblo". Tosco, Agustín "Unidad en la lucha”, Nuevo Hombre N ${ }^{\circ}$ 61,18 de abril de 1974, en De Santis, 2004, p. 142.

58 "Acto por los Presos", revista Posición, abril/mayo de 1973: 8. CPM - FONDO DIPBA División Central de Documentación, Registro y Archivo, Mesa “D (S)”, Carpeta Varios, Legajo 6318.

59 Boletín de Información de COFAPPEG, Año 1, No3 (marzo 1974) y 4 (mayo 1974). También encuentro esta referencia en la Solicitada "Al PUEBLO de Mar del Plata", publicada tras la reforma del Código Penal en enero de 1974. CPM - FONDO DIPBA División Central de Documentación, Registro y Archivo, Mesa “A”, Factor Político, Carpeta N 37, Legajo 272.

60 Boletin de Información de COFAPPEG, Año 1, N 4 (mayo 1974), p. 31. Archivo digital Fundación Pluma. 